\title{
Pontos (In)comuns nos Processos de Formação de Professores de Matemática Identificados ao Longo de Quase Duas Décadas (2000-2017)
}

\author{
Un(common) Points in the Training Processes of Mathematics Teachers Identified Over \\ Nearly Two Decades (2000-2017)
}

\author{
Marlúbia Corrêa de Paula1* \\ Pontifícia Universidade Católica do Rio Grande do Sul (PUCRS). \\ Alessandra Fabian Sostisso2** \\ Faculdade Mário Quintana - (FAMAQUI) \\ Caroline da Silva Petró3 ${ }^{* * *}$ \\ Pontifícia Universidade Católica do Rio Grande do Sul - (PUCRS) \\ Reinaldo Feio Lima4 ${ }^{* * * *}$ \\ Universidade Federal do Sul e Sudeste do Pará-(UNIFESSPA)
}

\begin{abstract}
Resumo
Neste artigo foram contabilizados artigos publicados em quatro revistas eletrônicas com Qualis A-1 e B-1. Nessas revistas procurou-se quais seriam as questões (in)comuns que têm norteado os processos de formação de professores. Trata-se, assim, de uma pesquisa qualitativa com abordagem fenomenológica, realizada por meio de busca documental e bibliográfica. O método de análise utilizado foi a metaanálise. Para esse fim, selecionou-se um total de 40 artigos, tendo sido localizados, entre estes, sete artigos de universidades da Espanha e um de Honduras. Dado o número de trabalhos selecionados, foi possível determinar o quanto as publicações de diferentes revistas apontavam, naquele momento, para diferentes ações formativas. Conclui-se que foram constatadas 30 características nos 40 artigos analisados. Alguns temas foram identificados simultaneamente em diferentes revistas, o qual referia-se ao modo como o professor se comunica em sala de aula. Políticas públicas voltadas às ações dos professores estiveram presentes numa ocorrência de dois artigos. $\mathrm{O}$ uso de tecnologias pelos professores em formação foi uma questão abordada em quatro dos 40 artigos selecionados. O tema apresentado numa maior frequência entre as publicações dessas revistas foi a preocupação em desenvolver conteúdos matemáticos. Essa questão foi manifestada em seis artigos (estudo sobre funções, geometria, números decimais e conjuntos numéricos na educação básica; estatística, limites e continuidades no ensino superior). Pode-se afirmar, também, que a característica da formação de professores, realizada no período referente à década de 60 , onde havia uma preocupação conteudista, é ainda a maior presença, devido aos dados levantados neste artigo.
\end{abstract}

Palavras-chave: Processos de formação de professores, Matemática, Pontos incomuns.

\footnotetext{
* Doutora. Pontifícia Universidade Católica do RS (PUCRS). E-mail: paula.metodologias@gmail.com

** Mestre. Pontifícia Universidade Católica do Rio Grande do Sul. Professora titular de Introdução à Matemática e Estatística, Matemática Financeira e Probabilidade e Estatística na Faculdade Mário Quintana (FAMAQUI), Porto Alegre RS, Brasil. E-mail: alesostisso@gmail.com

***Mestre. Pontifícia Universidade Católica do Rio Grande do Sul.. E-mail: caroline.matematica@gmail.com **** Mestre. Pontifícia Universidade Católica do Rio Grande do Sul (PUCRS). Professor Assistente da área temática Educação Matemática na Universidade Federal do Sul e Sudeste do Pará (UNIFESSPA), Marabá, Pará, Brasil. E-mail: reinaldo.lima@unifesspa.edu.br
} 


\begin{abstract}
In this article, were counted articles published in four electronic journals with Qualis A-1 and B-1. These journals sought to identify the (un)common issues that have guided the processes of teacher training. It is, therefore, a qualitative research with a phenomenological approach, accomplished through documentary and bibliographic search. The analysis method used was meta-analysis. For this purpose, a total of 40 articles were selected, among which were seven articles from universities in Spain and one from Honduras. Given the number of papers selected, it was possible to determine how much the publications of different journals pointed, at that moment, to different formative actions. It was concluded that 30 characteristics were found in 40 articles analyzed. Some themes were identified simultaneously in different journals, which referred to how the teacher communicates in the classroom. Public policies focused on teachers' actions were present in an occurrence of two articles. The use of technologies by teachers in training was an issue addressed in four of the 40 articles selected. The theme presented in a higher frequency among the publications of these magazines was the concern in developing mathematical contents. This question was expressed in six articles (study on functions, geometry, decimal numbers and numerical sets in basic education, statistics, limits and continuities in higher education). It can also be said that the characteristic of teacher education, which was carried out during the $60 \mathrm{~s}$, where there was a content concern, is still the greatest presence, due to the data presented in this article.
\end{abstract}

Keywords: Teachers' training processes, Mathematics, Uncommon points.

\title{
1 Introdução
}

Neste estudo apresenta-se uma meta-análise sobre o enfoque "O que há de (in)comum nos processos de formação de professores de matemática ao longo de quase duas décadas (20002017)". Para isso, foram identificadas publicações em quatro revistas eletrônicas. O critério escolhido foi o que classifica as revistas no sistema Qualis. Dessa forma, deu-se preferência àqueles classificados dentro do QUALIS A-1 e B-1, respectivamente: Revista de Educação Matemática (ZETETIKE), Boletim de Educação Matemática (BOLEMA), Revista Latinoamericana de Investigación en Matemática Educativa (RELIME) e Educação Matemática Pesquisa (EMP).

Para tanto, foi realizada a leitura dos resumos, e, em alguns casos, dos artigos na íntegra. Esse processo resultou na seleção de 40 artigos, que descreveram em seus objetivos intenções de descrever processos de formação de professores de Matemática, no período 2000-2017. Após esse espaço de leitura e distinção dos elementos dos artigos, verificou-se que a descrição da formação de professores de Matemática ocorreu mediante a presença de temas diversos.

Em 40 artigos foram identificados 30 temas que ora tratam da necessidade de um processo de formação como um período em que os conteúdos (estatística, geometria, conjuntos numéricos, multiplicação de decimais, estudo da função na educação básica; limites e continuidades no ensino superior) devessem ser melhor estruturados para o ensino na educação básica, ora mencionam o uso de tecnologias, citando os laboratórios de informática e de redes 
sociais.

A abordagem quali-quanti foi identificada num único artigo desta seleção, do total selecionado; nos demais artigos, a abordagem utilizada foi a qualitativa. Paralelamente, observou-se a predominância do verbo investigar nos objetivos dos artigos, seguidos de outros como: verificar, analisar, discutir e produzir.

Dentre os objetivos, foi possível perceber que as crenças e a prática na formação de professores de Matemática tiveram predominância. O contexto ficou centrado em torno do Ensino Superior. Como instrumentos de coleta de dados, os questionários apareceram em maior número. Por isso, sem pretender outras antecipações, passa-se à fundamentação teórica.

\section{Aspectos Metodológicos E Fundamentação Teórica}

Este artigo está estruturado dentro de uma abordagem fenomenológica, pois o fenômeno da formação de professores de Matemática foi observado no contexto apresentado pelos artigos analisados. Dessa forma, busca-se compreender o fenômeno sem pretender interferir na sua ocorrência. Para contribuir com o esclarecimento sobre esse tipo de pesquisa, utilizam-se leituras realizadas segundo as compreensões de Fazenda (2010, p.68):

Método fenomenológico é a atitude de abertura do ser humano para compreender o que se mostra (abertura no sentido de estar livre para aprender o que se mostra (abertura no sentido de estar livre para perceber o que se mostra e não preso a conceitos ou predefinições). Estamos livres quando sabemos de nossos valores, conceitos e preconceitos e podemos ver o que se mostra cuidando das possíveis distorções.

Wolf (1986) ratifica que a técnica da meta-análise não é universal, perfeita ou infalível, sendo, assim, sequencial à bibliográfica. Logo, cabe ao pesquisador ter o conhecimento desta técnica para que a utilize de modo adequado. Para Fiorentini e Lorenzato (2006, p.106), a metaanálise é "[...] uma revisão sistemática de outras pesquisas, visando realizar uma avaliação crítica das mesmas e/ou produzir novos resultados ou síntese a partir do confronto desses estudos, transcendendo aqueles anteriores obtidos". Nesse sentido, ela é caracterizada como uma técnica quantitativa (Luis, 2002, Rosenthal, 1995, Dimatteo, 2001) que inclui “[...] resultados de estudos realizados de forma independente" para "[...] sintetizar suas conclusões ou mesmo extrair uma nova conclusão" (Luis, 2002, p. 409).

Contudo, o método se aplica apenas às abordagens qualitativas. Para o autor, a caracterização descritiva interpretativa estaria na identificação "[...] de determinadas categorias, semelhanças e controvérsias numa quantidade de estudos da mesma área de pesquisa" (Rodrigues, 2009, p.26). Neste artigo, a meta-análise possibilitou que fossem criadas categorias 
emergentes para a descrição dos casos analisados em cada artigo, que deram origem aos subtítulos descritos na sequência deste texto.

\subsection{A Comunicação Dos Professores De Matemática Em Sala De Aula E O Papel Das Crenças}

Considerando os resultados identificados. Apresenta-se o Quadro 1, no qual expõem-se todas as categorias emergentes das leituras realizadas desses artigos.

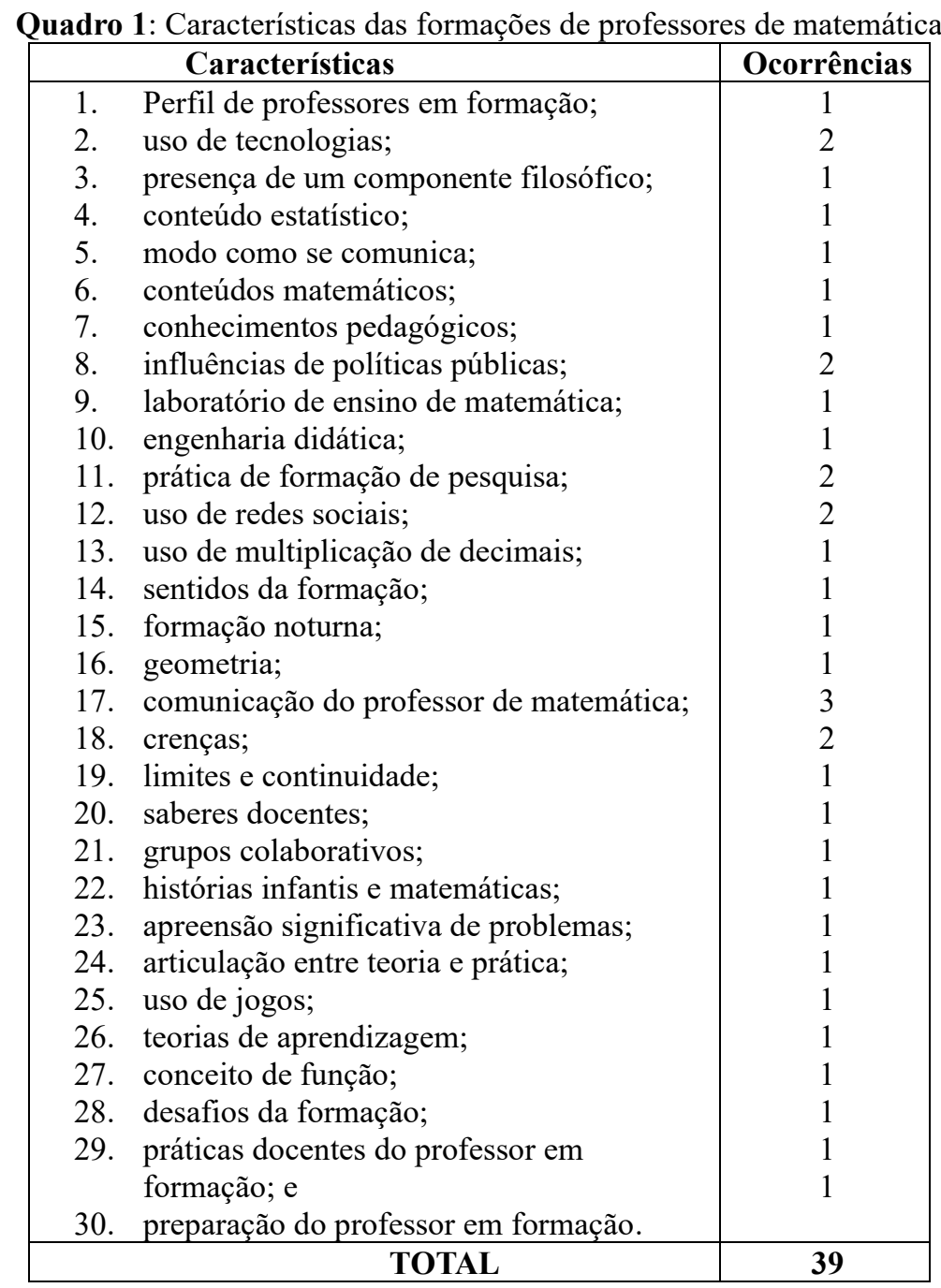

Fonte: Elaborado pelos autores (2019)

Dentre as ocorrências apresentadas, pode-se afirmar que há aspectos que ressaltam e outros que contribuem para a manutenção da diversidade de características. É provável que tratar o modo como os professores fazem as suas comunicações em sala de aula tenha relevância na formação de um professor. Se para comunicar o professor faz uso de diversos elementos de 
seu repertório discursivo, então, em se tratando da atividade de professores em sala de aula, certamente que as crenças (com duas ocorrências) refletem aquilo em que acreditam e o que ensinam, por meio das práticas realizadas.

Por sua vez, as crenças são subjetivas, próprias do indivíduo, e baseadas na realidade que o professor vivência e nas suas ações e expectativas. Por isso é certo que as atividades dos professores têm muito (mas nem tudo) de suas crenças (Thompson, 1992).

Destarte, para Raymond (1997), as crenças não determinam por si as ações dos professores, mas exercem influências em suas práticas. Isso é revigorado por Serrazina (1999), pois, para essa autora, os professores já trazem em sua formação experiências e ações que podem refletir diretamente sobre suas ações na prática educativa. Pois, é preciso realizar investimentos “[...] numa formação que busque a articulação desses saberes, de modo a formar o professor como um profissional reflexivo e investigador de sua prática pedagógica [...]", conforme Cyrino (2006, p.81).

Para Tardif (2003, p.39), “o professor ideal é alguém que deve conhecer a sua matéria, sua disciplina e seu programa, além de possuir certos conhecimentos relativos às ciências da educação e à pedagogia e desenvolver um saber prático baseado em sua experiência [...]". Novamente, retomando o que está presente no Quadro 1, percebe-se que, de certa forma, ainda se busca ter o "professor ideal de Tardif", pois as categorias emergentes dos artigos analisados mencionam que em seis das ocorrências, os conteúdos devem ser uma preocupação dos processos de formação dos professores.

Conforme Ferreira (apud Fiorentini, 2009, p.20), em sua obra "Formação de professores de matemática: explorando novos caminhos com outros olhares", as formações de professores não eram comuns até a década de 60 , pois essa formação,

além dos cursos de licenciatura, consistia basicamente de programas emergenciais voltados para a solução de problemas com o número necessário de professores. Isso conduziu, por exemplo, a criação de esquemas de treinamento de emergência, de qualidade duvidosa.

Dessa forma, Schön (1983 apud Ribeiro, 2009, p. 2) alerta que o programa de formação continuada só terá êxito se

for oferecida aos professores a oportunidade de refletir sobre os seus próprios conhecimentos e crenças, sendo este um possível ponto de partida para a mudança escolhida pelo professor. A reflexão deverá, assim, ser parte integrante de todo o processo de ensino sobre a reflexão na ação e sobre a ação.

Por isso, ressalta-se o processo de pesquisa como contribuinte para um genuíno contato pedagógico, pois nesse processo 
está o genuíno contato pedagógico, transformando em ambiente de trabalho conjunto, implicando, na mesma matriz, a qualificação do e pelo conhecimento e sua humanização constante e radical. Ai se vence o mero treinamento e se incrementa a emergência do sujeito capaz de crítica e projeto próprio para reconstruir eticamente (DEMO, 2007, p.66, grifo nosso).

Demo (2007) coloca a questão da diferença que há entre ter-se professores apenas treinados e professores conscientes de seu papel na sociedade, pois é por meio da pesquisa que pode ocorrer a transformação do entorno no qual se vive, afinal a pesquisa é o potencial gerador de, nas palavras do autor, questionamento reconstrutivo, pois “[...] esta educação será tanto mais emancipatória, quanto mais se escudar no questionamento reconstrutivo" (Demo, 2007, p.67).

Para interferir com qualidade formal e política, é necessário que as práticas docentes passem pelo viés da pesquisa, sinaliza ainda Demo (2007), posto que um dos sentidos da educação pela pesquisa, em que o agente é o professor pesquisador, é possibilitar que os estudantes desenvolvam competências, ou seja, deixem de ser o objeto de ensino e passem a fazer parte do processo. Em relação aos elementos identificados após a análise dos 40 artigos selecionados, foram detalhadas algumas características desses processos de formação de professores de Matemática.

\section{Diversidades Presentes Na Formação De Professores De Matemática (2000-2017)}

Dada a extensão de características apresentadas pelos processos de formação de professores de Matemática, foi realizada a descrição a partir dos seguintes dados: identificação da revista, título do artigo e objetivo ao qual se refere. Com esse fim, adotou-se o seguinte modelo de registro: cada trabalho foi identificado como um a dez, utilizando-se, para isso, os numerais romanos (I a X), já que foram selecionadas nesta investigação quatro revistas. A essa numeração foi adicionada a inicial de cada revista como identificação. Para tanto, cada uma dessas revistas recebeu um código identificador: ZETETIKE foi identificada como Z (I-X); BOLEMA como B (I-X); RELIME como R (I-X) e REM (I-X).

\subsection{Revista ZETETIKÉ E A Formação De Professores De Matemática}

Nesta revista foram selecionados dez artigos do período entre 2005-2013. O primeiro artigo identificado trata, curiosamente, de questionar: quem quer ser professor de Matemática? O termo curioso advém do fato de que essa indagação não é incomum em termos de assuntos tratados em cursos de formação de professores. Esse artigo, identificado como Z-I, foi o único 
em que os autores descrevem o perfil de diversas turmas de discentes do curso de Matemática.

Para quem pertence à área de formação desses professores é perceptível que o perfil delineado está consoante à realidade discente localizada em cursos de graduação presentes aqui no RS. Afirma-se isso por reconhecer nestas características outras já apresentadas em diversos mapeamentos locais.

Desse modo, esse artigo conduzia a uma ideia geral sobre as características peculiares daqueles acadêmicos que pretendiam, naquela ocasião, tornar-se professores de Matemática. Dessa forma, esse jovem acadêmico, que vem de escola pública e que está tendo acesso a uma educação de nível superior àquela recebida por seus pais, enfrenta desafios e possibilidades de trabalhos com projetos e com tecnologias, como se pode observar no trabalho descrito em Z-II. Ocorre o reconhecimento de que é necessário que exista na formação um componente filosófico, como o que advém de Z- III. Preocupações com uma formação voltada à condução de conteúdos e uma voltada à estatística foi manifestada em Z-IV. Indo além dos conteúdos, preocupam-se com a questão pedagógica da administração dos saberes voltados ao ensino e aprendizagem, como o que está registrado em Z-VI. Também ocorre uma atenção dispensada à comunicação realizada por esses professores em sala de aula $(\mathrm{Z}-\mathrm{V})$. As políticas públicas foram elemento de interesse em Z-VII e VIII.

Os laboratórios de informática aparecem como espaço de formação de professores de Matemática como o que está registrado em Z-IX. As reflexões do professor sobre as suas práticas foram comentadas em Z-X, com uso de Engenharia Didática.

O curioso é que em dez artigos há praticamente dez temáticas utilizadas em processos de formação de professores de Matemática, como se pode visualizar a seguir. Mas essa característica foi recorrente nas buscas realizadas que resultaram das leituras sobre as quatro revistas selecionadas. No entanto, em nenhum dos artigos identificados há detalhamento dos resultados positivos ou negativos sobre os processos de formação de professores de Matemática.

Quadro 2: Artigos selecionados na revista ZETETIKÉ sobre formação de professores de matemática (2005-2013)

\begin{tabular}{|c|c|c|}
\hline \multicolumn{3}{|c|}{ REVISTA ZETETIKÉ } \\
\hline Ano/Número & Título & Objetivo \\
\hline 2013 / Z-I & $\begin{array}{l}\text { Quem quer ser professor de } \\
\text { matemática? }\end{array}$ & $\begin{array}{l}\text { Estudo relata o perfil dos ingressantes nos cursos de } \\
\text { Licenciatura em Matemática no Brasil, realizado com } \\
664 \text { alunos de licenciaturas de } 19 \text { IES de } 10 \text { estados } \\
\text { brasileiros, nos anos de } 2008-2010 \text {. O estudo apontou } \\
\text { que jovens com maior nível escolar que os próprios } \\
\text { pais, que não são responsáveis pelo sustento da família } \\
\text { e que advêm de escola pública, são os que procuraram }\end{array}$ \\
\hline
\end{tabular}




\begin{tabular}{|c|c|c|}
\hline & & naqueles anos cursos de licenciatura de Matemática. \\
\hline 2013 / Z-II & $\begin{array}{l}\text { Desafios e possibilidades } \\
\text { do trabalho com projetos e } \\
\text { com tecnologias na } \\
\text { licenciatura em matemática }\end{array}$ & $\begin{array}{l}\text { O uso de projetos e tecnologias na licenciatura foi o } \\
\text { foco deste artigo, nas dimensões de formação } \\
\text { específica, pedagógica e tecnológica. Apontam que os } \\
\text { projetos propiciam na formação o desenvolvimento e } \\
\text { aprofundamento de conhecimentos de uso de } \\
\text { softwares no estudo da Matemática. }\end{array}$ \\
\hline 2013 / Z-III & $\begin{array}{l}\text { Em que a filosofia da } \\
\text { diferença e a arte } \\
\text { contemporânea podem } \\
\text { servir à formação de } \\
\text { professores de Matemática? }\end{array}$ & $\begin{array}{l}\text { O propósito do artigo foi explorar o funcionamento de } \\
\text { alguns dispositivos da contemporaneidade, tanto } \\
\text { filosófico como artísticos, que podem movimentar o } \\
\text { currículo de curso de Licenciatura em Matemática. }\end{array}$ \\
\hline 2012 / Z-IV & $\begin{array}{l}\text { A formação estatística e } \\
\text { pedagógica do professor de } \\
\text { matemática }\end{array}$ & $\begin{array}{l}\text { Quais as práticas os professores formadores citaram } \\
\text { desenvolveram ou valorizaram para evidenciar e } \\
\text { fortalecer os nexos entre as práticas de formação } \\
\text { estatística e as de formação pedagógica. }\end{array}$ \\
\hline $2010 / \mathrm{Z}-\mathrm{V}$ & $\begin{array}{l}\text { A comunicação promovida } \\
\text { por futuros professores na } \\
\text { aula de matemática }\end{array}$ & $\begin{array}{l}\text { Analisar o comportamento de dois professores em } \\
\text { formação em relação ao modo como utilizam a } \\
\text { comunicação em sala de aula, pois esses dois } \\
\text { professores apresentam concepções e práticas } \\
\text { diferentes. }\end{array}$ \\
\hline $2010 / \mathrm{Z}-\mathrm{VI}$ & $\begin{array}{l}\text { A relação r conhecimento } \\
\text { matemático r versus } \\
\text { conhecimento pedagógico } \\
\text { na formação do professor de } \\
\text { matemática: um estudo } \\
\text { histórico. }\end{array}$ & $\begin{array}{l}\text { Neste artigo também se retoma a discussão que tem } \\
\text { perpassado épocas pois, mais uma vez, trata da falta } \\
\text { de articulação entre conhecimentos matemáticos e } \\
\text { conhecimentos pedagógicos. Ou, saberes específicos e } \\
\text { saberes pedagógicos na formação dos professores de } \\
\text { Matemática. Para isso, utilizam as experiências } \\
\text { pessoais de professores de Matemática como Benedito } \\
\text { Castrucci, Ubiratan D’Ambrósio e Oswaldo } \\
\text { Sangiorgi. Usam, assim, fontes documentais como } \\
\text { depoimentos, artigos de jornal, anotações de aulas e } \\
\text { livros didáticos de autoria desses personagens. }\end{array}$ \\
\hline 2009 / Z-VII & $\begin{array}{l}\text { As influências das políticas } \\
\text { públicas curriculares na } \\
\text { constituição da identidade } \\
\text { do professor de matemática: } \\
\text { análise de um caso. }\end{array}$ & $\begin{array}{l}\text { Políticas públicas na constituição do professor foi a } \\
\text { escolha deste artigo, abordando diretamente o caso de } \\
\text { uma professora, conspirando os aspectos de sua } \\
\text { identidade profissional diante das dificuldades de um } \\
\text { currículo imposto. Pois, havia ali dificuldades geradas } \\
\text { pela falta de um trabalho coletivo na escola e de uma } \\
\text { formação política que desse sustentação a essa } \\
\text { reforma curricular. }\end{array}$ \\
\hline 2009 / Z-VIII & $\begin{array}{l}\text { Formação profissional de } \\
\text { professores de matemática } \\
\text { em serviço e políticas } \\
\text { públicas. }\end{array}$ & $\begin{array}{l}\text { Estudar as contribuições e limitações de um curso } \\
\text { emergencial de LP Parcelada em Matemática para a } \\
\text { formação e desenvolvimento profissional de } \\
\text { professores leigos em serviço. Destaque para o caso de } \\
\text { um professor-aluno que relatou e evidenciou } \\
\text { contribuições e limitações dessa formação } \\
\text { profissional, sobretudo em relação aos seus saberes e } \\
\text { práticas docentes em geometria. }\end{array}$ \\
\hline 2007 / Z-IX & $\begin{array}{l}\text { O laboratório de ensino de } \\
\text { matemática: implicações na } \\
\text { formação de professores. }\end{array}$ & $\begin{array}{l}\text { O papel do laboratório de ensino de Matemática na } \\
\text { formação do professor. Para isso, analisou um projeto } \\
\text { de estágio da PUC-Campinas, realizado com } 45 \text { alunos } \\
\text { da } 8^{\mathrm{a}} \text { série de uma escola pública, após ter sido } \\
\text { identificada insatisfação de alunos com relação à } \\
\text { Matemática e dificuldades de álgebra. Com o uso do } \\
\text { laboratório, tanto os alunos como os professores } \\
\text { envolvidos relataram ter obtido outras aprendizagens, } \\
\text { reconhecendo o laboratório como essencial no } \\
\text { processo e formação tanto inicial como continuada. }\end{array}$ \\
\hline $2005 / Z-X$ & Engenharia didática: um & Descreve o estudo de caso de atividade formadora de \\
\hline
\end{tabular}




\begin{tabular}{|l|l|l|}
\hline & referencial para ação & professores de Matemática, informada e orientada \\
investigativa e para & elos princípios da Engenharia Didática. O artigo \\
formação de professores de & apresenta um mapa da engenharia como exemplo de \\
matemática. & $\begin{array}{l}\text { roteiro racional para as reflexões do professor, em } \\
\text { formação inicial ou continuada, e que abrange: } \\
\text { descrição, justificativa e escolha do local do tema. }\end{array}$ \\
\hline
\end{tabular}

Fonte: Elaborado pelos autores (2019).

Após a identificação dos dez artigos acima mencionados, observou-se que, na leitura dos próximos dez artigos, surgiram outras questões presentes nos processos de formação de professores de Matemática, conforme o Quadro 2.

\subsection{Revista BOLEMA: Formação De Professores De Matemática}

De início, já se pode perceber que as práticas de formação e de pesquisa, voltadas ao professor que ensina matemática, foram elementos de discussão em B-I e B-IX. Neste último, a autora faz a abordagem por meio de resumo sobre um livro didático em que se discute o ensino de conjuntos numéricos e a necessidade dos saberes dos professores para realizar tal abordagem, com a devida propriedade de ideias baseadas em coerências matemáticas. Outros pontos necessários à formação são identificados ao longo dos artigos apresentados de B-II até B-X.

As redes sociais e intelectuais foram utilizadas para analisar artigos publicados na própria BOLEMA sobre formação de professores. Esse artigo apresenta um levantamento sobre a formação e está presente em B-II. Outro artigo que também apresenta um levantamento sobre a formação de professores de Matemática está em B- IV. Nessa ocasião, os autores apresentam as publicações realizadas na BOLEMA que resultam de 23 anos. Essa busca foi realizada em torno da apropriação nesses trabalhos voltada ao sentido da formação de professores de Matemática. A busca por significados do processo de formação foi realizada em B-VI. Esse artigo foi o único identificado num ambiente de formação de Mestrado profissionalizante. Formação, uso de tecnologias e estágio foram objetos de descrições em B-III.

A exemplo do que ocorreu nas publicações da ZETETIKE em relação à questão de conteúdos, também ocorreu nesta seleção de artigos publicados na BOLEMA. Desta vez, a escolha recaiu sobre números decimais, como o que se pode observar em B-V.

Quadro 3: Artigos selecionados na revista BOLEMA sobre a formação de professores de matemática (2006-2017)

\begin{tabular}{|c|l|l|}
\hline \multicolumn{4}{|c|}{ REVISTA BOLEMA } \\
\hline Ano & \multicolumn{3}{|c|}{ Título } & \multicolumn{1}{c|}{ Objetivo } \\
\hline 2017 / B-I & Práticas de formação e de & Ao narrar sua experiência, o movimento que marcou a \\
& pesquisa do professor que ensina & formação docente nas últimas duas décadas vai se \\
& matemática: uma construção & delineando. Como ocorre com a maioria dos formadores \\
\hline
\end{tabular}




\begin{tabular}{|c|c|c|}
\hline & narrativa. & $\begin{array}{l}\text { de professores, a autora se constituiu formadora pela } \\
\text { prática. }\end{array}$ \\
\hline 2017 / B-II & $\begin{array}{l}\text { Formação de professores que } \\
\text { ensinam matemática: um olhar } \\
\text { sobre as redes sociais e } \\
\text { intelectuais. }\end{array}$ & $\begin{array}{l}\text { Análise de artigos publicados na BOLEMA (1985-2015) } \\
\text { para identificar a rede social e intelectual dos artigos que } \\
\text { tratam sobre o tema, por meio da metodologia de análise } \\
\text { de redes sociais (ARS) com auxílio do software Gephi. }\end{array}$ \\
\hline 2016/B-III & $\begin{array}{l}\text { O PROFMAT e a formação do } \\
\text { professor de matemática: uma } \\
\text { análise curricular a partir de uma } \\
\text { perspectiva processual e } \\
\text { descentralizadora. }\end{array}$ & $\begin{array}{l}\text { Analisa o artigo o currículo do PROFMAT a partir da } \\
\text { perspectiva processual e descentralizadora de Sacristán } \\
(1998 ; 2013) \text {, adotando como referências pesquisas cujo } \\
\text { objeto de estudo são os conhecimentos do professor que } \\
\text { ensina Matemática. }\end{array}$ \\
\hline 2012 / B-IV & $\begin{array}{l}\text { A formação do professor de } \\
\text { matemática, apoiada pelas TIC, } \\
\text { no seu estágio pedagógico. }\end{array}$ & $\begin{array}{l}\text { Artigo sobre o papel das TIC no desenvolvimento de } \\
\text { aspetos do conhecimento didático (tipo de tarefas e } \\
\text { formas de comunicação) e da capacidade reflexiva de } \\
\text { futuros professores de Matemática durante o seu estágio. }\end{array}$ \\
\hline 2009 / B-V & $\begin{array}{l}\text { A ‘formação do professor' e seus } \\
\text { sentidos em } 23 \text { anos do } \\
\text { BOLEMA: } 1985-2007 \text {. }\end{array}$ & $\begin{array}{l}\text { Apresentam-se aqui resultados de uma investigação que } \\
\text { teve por objetivo a análise dos artigos relacionados ao } \\
\text { campo formação de professores, em } 23 \text { anos de } \\
\text { publicação do BOLEMA - } 1985 / 2007 \text {. }\end{array}$ \\
\hline 2009 / B-VI & $\begin{array}{l}\text { Conhecimento matemático para } \\
\text { ensinar: uma experiência de } \\
\text { formação de professores no caso } \\
\text { da multiplicação de decimais. }\end{array}$ & $\begin{array}{l}\text { O conhecimento profissional de professores pode } \\
\text { influenciar de forma direta as oportunidades de } \\
\text { aprendizagem que facultam os seus alunos. Neste } \\
\text { trabalho, tratou-se do conhecimento sobre números } \\
\text { decimais, ficando evidente a falta de conhecimento dos } \\
\text { professores neste setor. }\end{array}$ \\
\hline 2008 / B-VII & $\begin{array}{l}\text { Contribuições para a formação } \\
\text { do professor de matemática } \\
\text { pesquisador nos mestrados } \\
\text { profissionalizantes na área de } \\
\text { ensino. }\end{array}$ & $\begin{array}{l}\text { Este ensaio apresentou resultados de investigações no } \\
\text { tema "formação de professores", em especial, formação } \\
\text { nos cursos de Mestrado profissionalizante da área de } \\
\text { ensino de Matemática e Ciências. }\end{array}$ \\
\hline 2008 / B-VIII & $\begin{array}{l}\text { Formação de professores de } \\
\text { matemática: desafios e direções. }\end{array}$ & $\begin{array}{l}\text { Neste artigo, o autor apresenta o trabalho desenvolvido } \\
\text { nos EUA para identificar e discutir dois focos da } \\
\text { pesquisa que podem auxiliar interessados a abordar } \\
\text { problemas e questões de formação de professores de } \\
\text { Matemática manifestados em todo o mundo. }\end{array}$ \\
\hline 2007 / B-IX & $\begin{array}{l}\text { O ensino noturno como palco } \\
\text { para a formação de licenciatura } \\
\text { em matemática. }\end{array}$ & $\begin{array}{l}\text { O objetivo desta pesquisa é identificar e verificar como } \\
\text { ocorre a integração e a complementação dos saberes } \\
\text { presentes na formação inicial dos alunos trabalhadores } \\
\text { noturnos, de um curso de Licenciatura em Matemática. }\end{array}$ \\
\hline 2006 / B-X & $\begin{array}{l}\text { A formação matemática do } \\
\text { professor: licenciatura e prática } \\
\text { docente escolar. }\end{array}$ & $\begin{array}{l}\text { Ao abordar as fases da formação do professor de } \\
\text { matemática, a autora traz uma discussão apresentada no } \\
\text { livro sobre os saberes referentes aos conjuntos } \\
\text { numéricos. }\end{array}$ \\
\hline
\end{tabular}

Fonte: Elaborado pelos autores (2019).

No trabalho identificado como B-VII, os desafios presentes na formação de professores de Matemática foram motivo de estudos. Semelhante ao perfil levantado no artigo publicado em Z-1, ocorreu em B-IIX uma pesquisa que buscava identificar e verificar como ocorria a integração e a complementação dos saberes presentes na formação inicial dos alunos trabalhadores noturnos, de professores de Matemática em formação. 


\subsection{Revista Relime: Formação De Professores De Matemática}

Os artigos selecionados na RELIME, também em número de dez, apresentados no Quadro 4, logo a seguir, sinalizam que o uso de vídeos para auxiliar na formação de professores primários era uma prática recorrente na Espanha, pois esse tema foi objeto de publicação, pelos mesmos autores, nos anos de 2013 e 2001.

Tais vídeos apresentavam crianças realizando atividades de Matemática e eram utilizados para que os discentes discutissem sobre procedimentos de ensino, quando ainda estavam em processo de formação.

Quadro 4: Artigos selecionados na revista RELIME sobre a formação de professores de matemática (2007-2013)

\begin{tabular}{|c|c|c|}
\hline \multicolumn{3}{|r|}{ REVISTA RELIME } \\
\hline Ano / Número & Título & Objetivo \\
\hline 2013 / R-I & $\begin{array}{l}\text { Conceptions and beliefs } \\
\text { of Honduran teachers } \\
\text { about teaching, learning } \\
\text { and assessment of } \\
\text { mathematics. }\end{array}$ & \\
\hline 2013 / R-II & $\begin{array}{l}\text { ¿Qué conocimientos y } \\
\text { concepciones movilizan } \\
\text { futuros maestros } \\
\text { analizando un vídeo de } \\
\text { aula? }\end{array}$ & $\begin{array}{l}\text { Neste artigo, os autores apresentam as contribuições do uso de } \\
\text { vídeos na educação primária, para formação inicial do professor, } \\
\text { como um método de vincular teoria e prática em relação aos } \\
\text { processos reflexivos, para auxiliar a transcender os habituais } \\
\text { comentários genéricos dos estudantes para professores. }\end{array}$ \\
\hline 2013 / R-III & $\begin{array}{l}\text { Identidades y competencias } \\
\text { profesionales de estudiantes } \\
\text { para maestro de la educación } \\
\text { infantil relativas a la } \\
\text { enseñanza de la geometría. }\end{array}$ & $\begin{array}{l}\text { O objetivo é investigar as manifestações e as avaliações de } \\
\text { habilidades profissionais e matemáticas envolvidas no ensino de } \\
\text { geometria escolar em uma amostra de sessenta e dois alunos para } \\
\text { professor de educação matemática }\end{array}$ \\
\hline $\begin{array}{l}2012 / \mathrm{R}- \\
\mathrm{IV}\end{array}$ & $\begin{array}{l}\text { Cognições e tipo de } \\
\text { comunicação do professor } \\
\text { de matemática. }\end{array}$ & $\begin{array}{l}\text { En este artículo centramos nuestra atención en el aula y, de manera } \\
\text { más concretas, en las acciones del profesor durante el proceso de } \\
\text { enseñanza, ya que consideramos que dichas acciones se ven } \\
\text { condicionadas o potenciadas por sus cogniciones (creencias, } \\
\text { conocimiento matemático para la enseñanza y objetivos). }\end{array}$ \\
\hline 2012 / R-V & $\begin{array}{l}\text { Conocimiento de futuros } \\
\text { profesores sobre la idea de } \\
\text { juego equitativo. }\end{array}$ & $\begin{array}{l}\text { En este trabajo se evalúan los conocimientos de } 167 \text { futuros } \\
\text { profesores de educación primaria en España respecto a un juego } \\
\text { equitativo. Para valorar el conocimiento común del contenido, se } \\
\text { analizaron las soluciones que dieron los docentes a dos problemas } \\
\text { abiertos. También se estudiaron dos componentes del conocimiento } \\
\text { didáctico, considerando el trabajo de los maestros en pequeños } \\
\text { grupos: para evaluar el conocimiento especializado del contenido, } \\
\text { se pidió a los participantes que identificaran los contenidos } \\
\text { matemáticos en la tarea, mientras que para determinar el } \\
\text { conocimiento del contenido y los estudiantes se les solicitó que } \\
\text { distinguieran, entre un grupo de respuestas a la tarea hecha por } \\
\text { alumnos de educación primaria, cuáles eran correctas e incorrectas. }\end{array}$ \\
\hline 2006 / R-VI & $\begin{array}{l}\text { Crenças, concepções e } \\
\text { conhecimento profissional } \\
\text { de professores que ensinam } \\
\text { cálculo diferencial a } \\
\text { estudantes de ciências } \\
\text { econômicas. }\end{array}$ & $\begin{array}{l}\text { Artigo que descreve as crenças, concepções e conhecimento } \\
\text { profissional de um grupo de professores que ensina cálculo } \\
\text { diferencial a estudantes de Ciências Econômicas. Professores } \\
\text { privilegiam a Matemática sobre o conteúdo econômico. }\end{array}$ \\
\hline 2005 / R-VII & $\begin{array}{l}\text { Creencias matemáticas y } \\
\text { la relación entre actores }\end{array}$ & $\begin{array}{l}\text { Crenças de um grupo de estudantes de práticas profissionais de } \\
\text { educação matemática. Quatro tipos de crenças foram identificadas }\end{array}$ \\
\hline
\end{tabular}




\begin{tabular}{|l|l|l|}
\hline & del contexto. & na concepção da matemática. \\
\hline 2001 / R-VIII & $\begin{array}{l}\text { Validación y } \\
\text { argumentación de lo } \\
\text { matemático en el aula. }\end{array}$ & $\begin{array}{l}\text { El uso del vídeo de sesiones de clase de Educación Primaria (EP) } \\
\text { en la formación inicial del maestro aporta realismo a las discusiones } \\
\text { teóricas de las aulas de magisterio, contribuyendo a la vinculación } \\
\text { entre la teoría y la práctica sobre la base de procesos reflexivos que } \\
\text { ayudan a trascender los habituales comentarios genéricos de los } \\
\text { estudiantes para maestro (EPM). }\end{array}$ \\
\hline 2000 / R-IX & $\begin{array}{l}\text { Concepciones de los } \\
\text { alumnos de Bachillerato y } \\
\text { curso de orientación } \\
\text { universitaria sobre limite } \\
\text { funcional y continuidad. }\end{array}$ & $\begin{array}{l}\text { Concepções dos alunos de bacharelado obre conteúdos adquiridos } \\
\text { durante o ensino recebido. }\end{array}$ \\
\hline $2000 /$ R-X & $\begin{array}{l}\text { Sobre la preparación de } \\
\text { los maestros de } \\
\text { matemáticas. }\end{array}$ & $\begin{array}{l}\text { O que aqui no Brasil já é consenso de que Vigotsky e Piaget podem } \\
\text { estar no mesmo texto, desde que se tenha atenção há alguns detalhes } \\
\text { é o que estava sendo discutido neste artigo na Espanha. }\end{array}$ \\
\hline
\end{tabular}

Fonte: Elaborado pelos autores (2019).

Identidades e competências profissionais foram manifestadas pela primeira vez nesta seleção de artigos em R-II. A forma como o professor se comunica em sala de aula foi objeto de R-III e já havia sido objeto de estudos em Z-V. Em R-IV, conhecimento e uso de jogos foram objeto deste artigo. R-V e R-VIII apresentaram as crenças e concepções atreladas ao cálculo diferencial e às Ciências Econômicas. R-VI discorreu diretamente sobre crenças matemáticas.

A comunicação também foi tema de estudos sob a terminologia de validação e argumentação em sala de aula, como o que se apresenta R-VII. R-IX aborda o processo de formação de professores, considerando a presença de teorias de aprendizagem com referenciais em Piaget e Vygotsky. De todos os artigos identificados apenas neste último citado ocorreu a descrição e preocupação com o uso de Teorias de Aprendizagem.

\subsection{Revista EMP: Formação De Professores De Matemática}

No próximo quadro, de número 5, passa-se à apresentação dos artigos identificados na EMP. O primeiro artigo menciona uma pesquisa sobre saberes, sobre a docência no ensino de geometria. Para isso, afirma a autora, " procuro aprender como aluna [...], procuro ter a visão de professora" (Cardim e Grando, 2011, p. 2).

A formação de professor de Matemática com apoio no uso de Tecnologias de Informação e Comunicação (TIC) também foi mencionada em EMP-II. Desafios durante a formação do professor de Matemática foi a temática discutida em EMP-III; demais elementos localizados são apresentados a seguir (Quadro 5).

Quadro 5: Artigos selecionados na revista EMP sobre a formação de professores de matemática (2006-2011)

\begin{tabular}{|c|c|c|}
\hline \multicolumn{3}{|c|}{ EDUCAÇÃO MATEMÁTICA E PESQUISA } \\
\hline Ano/ Número & Título & Objetivo \\
\hline 2011 / EMP-I & Saberes sobre a docência na & Esta pesquisa investiga a produção de saberes sobre a \\
\hline
\end{tabular}




\begin{tabular}{|c|c|c|}
\hline & $\begin{array}{l}\text { formação inicial de professores } \\
\text { de matemática. }\end{array}$ & $\begin{array}{l}\text { docência no ensino de geometria por licenciandos em } \\
\text { Matemática, em alguns espaços formativos no interior } \\
\text { da universidade. }\end{array}$ \\
\hline 2011 / EMP-II & $\begin{array}{l}\text { A formação do professor de } \\
\text { matemática, apoiada pelas TIC, } \\
\text { no seu estágio pedagógico. }\end{array}$ & $\begin{array}{l}\text { O artigo investiga as concepções dos professores } \\
\text { formadores em um curso de licenciatura em Matemática } \\
\text { em relação à ludicidade e compreender como utilizam } \\
\text { esse conceito em suas aulas, apresentando o que resultou } \\
\text { sobre a prática docente de sete professores deste curso. }\end{array}$ \\
\hline 2011 / EMP-III & $\begin{array}{l}\text { O professor formador e os } \\
\text { desafios da formação inicial de } \\
\text { professores de matemática. }\end{array}$ & $\begin{array}{l}\text { Este artigo discute os desafios enfrentados pelos } \\
\text { professores formadores nos cursos de licenciatura em } \\
\text { Matemática do estado de Minas Gerais. }\end{array}$ \\
\hline 2009 / EMP-IV & $\begin{array}{l}\text { Continuent les Petits Enfants à } \\
\text { ne pas Savoir Faire Additions? }\end{array}$ & $\begin{array}{l}\text { Analisa o modo como os alunos têm acesso ao conteúdo } \\
\text { matemático em séries iniciais. Questiona se a didática } \\
\text { matemática de fato modificou o modo de ensinar essa } \\
\text { disciplina ao longo dos anos. Considera as reformas dos } \\
\text { anos de } 60-70 \text { como base para comparações realizadas } \\
\text { no ano de } 2009 \text {. Esse artigo foi escrito a partir da } \\
\text { Universidade Pública de Navarra, Espanha. }\end{array}$ \\
\hline $2009 / \mathrm{EM}$ & 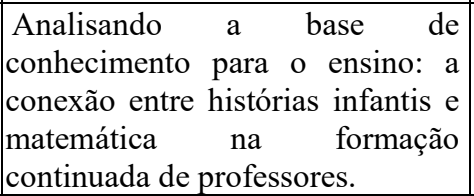 & $\begin{array}{l}\text { Esse artigo é parte de um projeto onde se observou o uso } \\
\text { de histórias infantis conectadas com a matemática na } \\
\text { formação e na prática docente. }\end{array}$ \\
\hline 2008 / EMP-VI & $\begin{array}{llr}\text { Formação de } & \text { professores de } \\
\text { matemática } & \text { e } & \text { apreensão } \\
\text { significativa } & \text { de } & \text { problemas } \\
\text { envolvendo } & \text { provas } & \text { e } \\
\text { demonstrações. } & & \end{array}$ & $\begin{array}{l}\text { O artigo apresenta uma reflexão sobre prova e } \\
\text { demonstração em matemática e discute alguns } \\
\text { resultados sobre um conjunto de atividades envolvendo } \\
\text { o raciocínio dedutivo, realizadas por professores de } \\
\text { ensino fundamental. }\end{array}$ \\
\hline 2007 / EMP-VII & $\begin{array}{l}\text { A articulação entre teoria e } \\
\text { prática na formação inicial de } \\
\text { professores de matemática. }\end{array}$ & $\begin{array}{l}\text { Investiga a articulação entre teoria e prática no processo } \\
\text { de formação inicial de professores de Matemática; } \\
\text { articulação teoria e prática; comunidade de prática. }\end{array}$ \\
\hline 2009 / EMP-VIII & $\begin{array}{l}\text { Formação continuada em grupos } \\
\text { colaborativos: professores de } \\
\text { matemática iniciantes e as } \\
\text { aprendizagens da prática } \\
\text { profissional. }\end{array}$ & $\begin{array}{l}\text { Analisa a participação em grupos colaborativos a } \\
\text { formação e a aprendizagem do professor de matemática } \\
\text { a em início de careira. São abordadas teoricamente as } \\
\text { características e problemas dos professores nesta fase da } \\
\text { profissão. }\end{array}$ \\
\hline 2007 / EMP-IX & 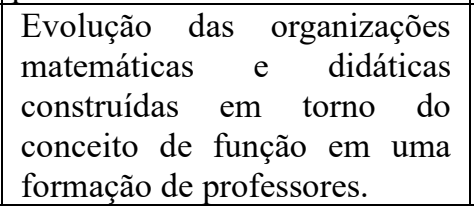 & $\begin{array}{l}\text { O artigo apresenta uma análise de professores da rede } \\
\text { pública de ensino do estado de SP, participantes de um } \\
\text { projeto de formação continuada. Esses professores } \\
\text { construíram e aplicaram sequência didática para ensino } \\
\text { e aprendizagem de funções numa turma de oitava série. }\end{array}$ \\
\hline
\end{tabular}

Fonte: Elaborado pelos autores (2019).

"Grupos colaborativos" foi a temática discutida em EMP VIII. A formação continuada foi o cenário de EMP-V, quando o projeto apresentado buscava conectar histórias infantis e ensino de Matemática. EMP-VI foi o artigo que discutiu o uso de provas e demonstrações como elemento de formação de professores de Matemática. Articular teoria e prática foi objeto de discussão em EMP-VII. A preocupação do conceito de função foi objeto de EMP-IX.

\section{Aproximações E Afastamentos Entre As Publicações Sobre Formação De Professores De Matemática: ZETETIKÉ, BOLEMA, RELIME E EMP}

Inicialmente, ao realizar a leitura dos artigos sobre a formação de professores de 
Matemática, pretendia-se discorrer sobre a questão das crenças que impedem a modificação das práticas pedagógicas de professores de Matemática, pois isso parecia ser uma questão própria de discussão dessa área. No entanto, com o andar da coleta de artigos, o que se verificou é que a formação de professores tem sido objeto de publicações sob diversos enfoques. Para resumir esta questão, apresentam-se os seguintes enfoques adotados nestes artigos.

\subsection{ZETETIKÉ}

Nessas publicações a formação foi tratada a partir de: estudo de perfil de professores, uso de tecnologias e projetos, emprego de filosofia da diferença e de arte contemporânea, estudo sobre estatística, o modo como se comunicam professores em salas de aula, relação conhecimento matemático versus pedagógico sem ala de aula, políticas públicas voltadas constituição da identidade do professor e formação profissional de professores em serviço(formação continuada), uso de laboratórios e implicações na formação, engenharia didática como um referencial para ação investigativa.

\subsection{BOLEMA}

Nessas publicações o enfoque foi dado a práticas de formação e de pesquisa do professor que ensina Matemática; formação de professores que ensinam Matemática, considerando as redes sociais e intelectuais; a formação do professor de matemática "apoiada" pelas TIC durante o Estágio Pedagógico; a 'formação do professor' e seus sentidos; o conhecimento matemático para ensinar multiplicação de decimais; contribuições para a formação do professor de matemática pesquisador nos mestrados profissionalizantes na área de ensino, discutindo sobre desafios e direções; o ensino noturno e a formação de Licenciatura em Matemática; a licenciatura e a prática docente escolar.

\subsection{RELIME}

Em publicações da RELIME, localizaram-se participações de autores da Espanha em cinco dos artigos que tratavam de

conhecimentos e concepções mobilizam futuros maestros com uso de vídeos de aulas; Identidades e competências professionais de estudantes para ensino da educação infantil relativas ao ensino de geometria e, conhecimento de futuros professores sobre a ideia de jogo equitativo; Crenças Matemáticas e a relação entre atores do contexto, validação e argumentação do conteúdo matemático em sala de aula, concepções dos alunos de Bacharelado e curso de orientação universitária sobre limite funcional e continuidade; a preparação dos professores de matemática. 
Preocupações com cognições e tipo de comunicação do professor de Matemática também foram objeto de estudos, assim como crenças, concepções e conhecimento profissional de professores que ensinam cálculo diferencial a estudantes de Ciências Econômicas.

\subsection{EMP}

Os temas tratados foram: saberes sobre a docência na formação inicial de professores de Matemática; formação do professor de Matemática, apoiada pelas TIC, no seu Estágio Pedagógico; o professor formador e os desafios da formação inicial de professores de matemática; a formação continuada em grupos colaborativos; histórias infantis e matemática na formação continuada de professores; apreensão significativa de problemas envolvendo provas e demonstrações; articulação entre teoria e prática na formação inicial de professores de matemática; formação continuada em grupos colaborativos; e, a evolução das organizações matemáticas e didáticas construídas em torno do conceito de função em uma formação de professores.

\section{Conclusões Anunciadas Dos Artigos Analisados}

Os processos de formação registrados nesses 40 artigos abordaram temas específicos sobre a necessidade de alguns conteúdos. Pelo que se percebe, discussões sobre teorias de aprendizagens foram abordadas com a mesma frequência que a preocupação com sentidos e significados sobre o que representa a formação de professores de Matemática para os discentes envolvidos nesse processo. Ou seja, essas abordagens ocorreram uma única vez. O uso de tecnologias foi uma preocupação manifestada em dois artigos, assim como o uso de vídeos para a formação de professores voltados à educação primária de professores espanhóis.

Ainda, o uso de rede social também foi mencionado uma só vez por autores brasileiros. Atenção à prática pedagógica foi dada a dois artigos e a mesma frequência foi relativa às crenças dos professores em formação. Os artigos não detalham quais são as crenças, mas afirmam que professores em formação realizam seus procedimentos em salas de aula do mesmo modo com que foram ensinados.

O que de fato predominou foi a preocupação com ensino de conteúdos. Como se pode verificar, na década de 60 essa era preocupação com os cursos de formação de professores de Matemática, pois, naquela época, era prerrogativa uma formação conteudista. Pode-se dizer que as lacunas na formação de professores de Matemática estão relacionadas com a estrutura 
curricular do curso de formação, o que afeta o papel da formação inicial e continuada no aprendizado de sua prática. Isso porque parte dos currículos de formação é destinada ao embasamento teórico e com isso disciplinas de formação teórico-prática nem sempre conseguem aproximar os futuros professores da realidade do ensino na sala de aula.

Deste fato, percebe-se que acaba inviabilizada a mudança de prática pedagógica, ou seja, o professor acaba levando para a sala de aula um pequeno repositório de alternativas para realizar o ensino e obter o consequente aprendizado de Matemática. Contudo, esse repositório está muito "preso" à formação que recebeu na própria formação básica, e, com isso, há um esforço de manutenção no modo como ensina Matemática.

Assim, ao analisar as produções que estavam ligadas aos saberes docentes de professores em formação continuada, registrou-se que é necessário lançar um olhar sobre a formação cultural, científica, pedagógica e disciplinar para que estas possam estar vinculadas à formação inserida em prática. Portanto, como resultante das análises realizadas, fica claro o quanto é necessária uma maior divulgação dos saberes mobilizados/construídos pelos professores durante a prática pedagógica nas salas de aula, em especial no que se refere aos saberes da experiência do próprio professor que realiza o ensino dos conteúdos (estatísticos, multiplicação de decimais, geometria, limites e continuidade).

Outra questão que chama a atenção é o fato da preocupação com os conteúdos e seus modos de ensino. Não que não seja pertinente tal interesse, mas esse fator lembra em muito a preocupação em realizar formações conteudista, como aquela que ocorreu durante os anos 60 . No momento de identificação dos artigos não foi detectado um movimento que sinalize modificações nesta área. No entanto, há preocupações quanto à presença do componente filosófico em formação de professores de Matemática aliado ao pensamento de que é preciso perceber quais são os sentidos da formação deste professor. Esses aspectos foram os únicos que se distanciaram de outros que se detêm numa formação centrada em ensino de conteúdos. Sendo assim, esta busca não sinalizou maior preocupação com alteração nesse modelo de formação para um professor de Matemática.

\section{Referências}

Almeida, M.G., \& Fernandes, J.A. (2010) A comunicação promovida por futuros professores na aula de matemática. Zetetike: Revista de Educação Matemática, v.18(34), 109-154. Recuperado de http://www.fae.unicamp.br/revista/index.php/zetetike/article/view/2818/ 2475 
Almouloud, Sado Ag. et al. (2008). Formação de professores de matemática e apreensão significativa de problemas envolvendo provas e demonstrações. Educação Matemática Pesquisa, v. 10(1), 217-246.

Baumann, A.P.P., \& Bicudo, M.A.V. (2009). Características da formação de professores de matemática dos anos iniciais do ensino fundamental com foco nos cursos de pedagogia e matemática. Bolema, v.22(32), [s.p.].

Cardim, V.R.C., \& Grando, R.C. (2011) Saberes sobre a docência na formação inicial de professores de matemática. Educação Matemática Pesquisa, v. 13(1),1-34.

Carneiro, V.C.G. (2008). Contribuições para a formação do professor de matemática pesquisador nos mestrados profissionalizantes na área de ensino. Bolema, v.21(29), 199222.

Carneiro, V.C.G. (2005). Engenharia didática: um referencial para ação investigativa e para formação de professores de matemática. Zetetike: Revista de Educação Matemática, v.13(23), 87-120. Recuperado de http://www.fae.unicamp.br/revista/index.php/zetetike/ article/view/2458/2220

Climent, N., Romero-Cortés, J.M, Carrillo, J., Muñoz-Catalán, M.C., \& Contreras, L.C. (2013). ¿Qué conocimientos y concepciones movilizan futuros maestros analizando un vídeo de aula? Relime, v. 16(1), 3-26.

Corredor, O.L.L., \& Calderón, D.I. (2001). Validación y argumentación de lo matemático en el aula. Relime, v. 4(1), 5-21.

Costa, V.G., \& Scriptori, C.C. (2011). Professor formador e a ludicidade no curso de licenciatura em matemática: reflexões advindas de uma pesquisa empírica. Educação Matemática Pesquisa, v. 13(1), 51-71.

Costa, V.G., \& Passos, L.F. (2009). O professor formador e os desafios da formação inicial de professores de matemática. Educação Matemática Pesquisa, v. 13(1), 597-623.

Curi, E., \& Pires, C.M.C. (2008). Pesquisas sobre a formação do professor que ensina matemática por grupos de pesquisa de instituições paulistanas. Educação Matemática Pesquisa, v. 10(1), 151-189.

D’amore, B., \& Martini, B. (2000). Sobre la preparación de los maestros de matemáticas. Relime, v. 3(1), 33-45.

Demo, P. (1998). Educar pela pesquisa. 3. ed. São Paulo: Autores Associados.

Duarte, A.R.S., Oliveira, M.C.de, \& Pinto, N.B. (2010). A relação conhecimento matemático versus conhecimento pedagógico na formação do professor de matemática: um estudo histórico. Zetetike: Revista de Educação Matemática, v.18(33), 103-136. Recuperado de: http://www.fae.unicamp.br/revista/index.php/zetetike/article/view/2801/2465.

Fazenda, I. (2010). Metodologia da pesquisa educacional. São Paulo: Cortez. 
Fiorentini, D., \& Lorenzato, S. (2009). Formação de professores de matemática: explorando novos caminhos com outros olhares. Campinas/SP: Autores Associados.

Fiorentini, D., \& Lorenzato, S. (2006). Investigação em educação matemática: percursos teóricos e metodológicos. Campinas/SP: Autores Associados.

Fürkotter, M., \& Morelatti, M.R.M. (2007). A articulação entre teoria e prática na formação inicial de professores de matemática. Educação Matemática Pesquisa, v. 9(2), 319-334.

Gama, R.P., \& Fiorentini, D. (2011). Formação continuada em grupos colaborativos: professores de matemática iniciantes e as aprendizagens da prática profissional. Educação Matemática Pesquisa, v. 13(1), 441-461.

García, L., Azcárate, C., \& Moreno, M. (2006). Crenças, concepções e conhecimento profissional de professores que ensinam cálculo diferencial a estudantes de ciências econômicas. Relime, v. 9(1), 85-116.

Lacasta, E.; Whihelme, M.; Belletich, O. (2009). Continuent les Petits Enfants à ne pas Savoir Faire Additions? Educação Matemática Pesquisa, v. 11(2), 303-328.

Laville, C., \& Dionne, J. (1999). A construção do saber. Manual de Metodologia de Pesquisa em Ciências Humanas. Porto Alegre: Artmed.

Lopes, J.A., \& Araujo, E.A. (2007). O laboratório de ensino de matemática: implicações na formação de professores. Zetetike: Revista de Educação Matemática, v.15(27), 57-70. Recuperado de http://www.fae.unicamp.br/revista/index.php/zetetike/article/view/2420/ 2182

Matheus, A.A.O., \& Nacarato, A.M. (2009). As influências das políticas públicas curriculares na constituição da identidade do professor de matemática: análise de um caso. Zetetike: Revista de Educação Matemática, v. 17(n. temático), 95-122. Recuperado de http://www.fae.unicamp.br/revista/index.php/zetetike/article/view/2575/2319

Moreira, P.C. et al. (2012). Quem quer ser professor de matemática? Zetetike: Revista de Educação Matemática, v.20(37), 11-34. Recuperado de http://www.fae.unicamp.br/ revista/index.php/zetetike/article/view/2850/3729

Nacarato, A.M. (2010). A formação matemática das professoras das séries iniciais: a escrita de si como prática de formação. Bolema, v. 23(37), 905-930.

Ortiz, J.J., Batanero, C., \& Contreras, J.M. (2012). Conocimiento de futuros professores sobre la ideia de juego equitativo. Relime, v. 15(1), 63-91.

Pamplona, A.S. (2012). A formação estatística e pedagógica do professor de matemática. Zetetike: Revista de Educação Matemática, v. 29(37), 91-105. Recuperado de http://www.fae.unicamp.br/revista/index.php/zetetike/article/view/2864/3732

Parra, H. (2005). Creencias matemáticas y la relación entre actores del contexto. Relime, v.8(1), 69-90. 
Passos, C.L.B., Oliveira, R.M.M.A., \& Souza, R.D. (2009). Analisando a base de conhecimento para o ensino: a conexão entre histórias infantis e matemática na formação continuada de professores. Educação Matemática Pesquisa, v. 13(1), 624-645.

Passos, M.M., Nardi, R., \& Arruda, S.M. (2009). A formação do professor e seus sentidos em 23 anos do Bolema: 1985-2007. Bolema, v. 22(34), 209-236.

Pérez, L.D.M. (1998). Modelos para la representación y procesamiento del conocimiento pedagógico em tutoriales inteligente. Relime, v. 1(2), 51-52.

Ponte, J.P.M., \& Viseu, F. (2012). A formação do professor de matemática apoiada pelas TIC no seu estágio pedagógico. Bolema, v. 26(42), 329-357.

Rehder, J.G., \& Passos, L.F. (2007). O ensino noturno como palco para a formação de licenciatura em matemática. Bolema, v. 20(27), [s.p.].

Reis, M.E.T., \& Fiorentini, D. (2009). Formação profissional de professores de matemática em serviço e políticas públicas. Zetetike: Revista de Educação Matemática, v.17(n. temático), 123-150. Recuperado de http://www.fae.unicamp.br/revista/index.php/zetetike/article/ view/2576/2320

Ribeiro, C.M. (2009). Conhecimento matemático para ensinar: uma experiência de formação de professores no caso da multiplicação de decimais. Bolema, v. 19(26), 1-26, 21.

Ribeiro, M.C., \& Carrillo, J.M.R. (2012). Cognições e tipo de comunicação do professor de matemática: exemplificação de um modelo de análise num episódio dividido. Relime, v. 15(1), 93-121.

Richit, A. (2006). A formação matemática do professor: licenciatura e prática docente escolar. Bolema, v. 19(25), 1-7.

Richit, A., \& Maltempi, M.V. (2010). Desafios e possibilidades do trabalho com projetos e com tecnologias na licenciatura em matemática. Zetetike: Revista de Educação Matemática, v.18(33), 15-42. Recuperado de http://www.fae.unicamp.br/revista/index.php/zetetike/ article/view/2796/2460.

Rodrigues, C.G. (2010). Em que a filosofia da diferença e a arte contemporânea podem servir à formação de professores de matemática? Zetetike: Revista de Educação Matemática, v.18(n. temático), 245-256. Recuperado de http://www.fae.unicamp.br/revista/index.php/ zetetike/article/view/2834/2491

Rodrigues, C. (2009). A abordagem processual no estudo da tradução: uma meta-análise qualitativa. Cadernos de Tradução, v. 2(10).

Rosenthal, R. (1995). Writing meta-analytic reviews. Psychological Bulletin, v.118(2), 183192.

Rossini, R. (2007). Evolução das organizações matemáticas e didáticas construídas em torno do conceito de função em uma formação de professores. Educação Matemática Pesquisa, v. $9(2), 205-247$. 
Sanhueza, S., Penalva, M.C., \& Fritz, M. (2013). Identidades y competencias profesionales de estudiantes para maestro de la educación infantil relativas a la enseñanza de la geometría. Relime, v. 16(1), 99-125.

Serrazina, L. (1999). Reflexão, conhecimento e práticas letivas em matemática num contexto de reforma curricular no $1^{\circ}$ ciclo. Quadrante, (8), 139-168.

Silver, E. (2008). Formação de professores de matemática: desafios e direções. Bolema, v. 19(26), 1-24.

Tardif, M.(2003). Saberes Docentes e Formação Profissional. Pretópolis: Vozes.

Thompson, A. (1992). Teachers' beliefs and conceptions: a synthesis of the research. In D.A. Grouws, (Ed.), Handbook of research on mathematics teaching and learning. (pp.127146). New York: Macmillan.

Vasconcellos, M., \& Bitar, M. (2007). A formação do professor para o ensino de matemática na educação infantil e nos anos iniciais: uma análise da produção dos eventos da área. Educação Matemática Pesquisa, v. 9(2), 275-292.

Vázquez, M.S., Astudillo, M.T.G., \& Esteban, C.L. (2000). Concepciones de los alumnos de bachillerato y curso de orientación universitaria sobre limite funcional y continuidad. Relime, v. 3(1), 71-85.

Viol, J.F. (2009). Conhecimento matemático para ensinar: uma experiência de formação de professores no caso da multiplicação de decimais. Bolema, v. 22(32), 241-246.

Wolf, F.M. (1986). Meta-analysis: quantitative methods for research synthesis. Newbury Park, CA: Sage.

Submetido em: 10/01/2014

Aprovado em: 12/08/2019 